Peter Jones

Stephane Dauger

\section{The benefits of nCPAP versus intubation for severe bronchiolitis}

Accepted: 7 February 2014

Published online: 13 March 2014

(C) Springer-Verlag Berlin Heidelberg and ESICM 2014

A reply to this comment can be found at doi:10.1007/s00134-014-3255-2.

\section{Dear Editor,}

We were interested to read the study by Essouri et al. [1] that presented data purporting to show the benefits of nasal continuous positive airway pressure (nCPAP) over tracheal intubation for severe bronchiolitis. This single-centre observational study retrospectively compares two different cohorts of children treated in equal time periods between 1996-2000 (intubation, $n=193$ ) and 2006-2010 (nCPAP, $n=332$ ). The methodology used to compare the clinical evolution was to retrospectively adjust a hazard ratio for duration of ventilatory support using the prognostic baseline covariates of PRISM score, age, gestational age RSV infection and antibiotic use.

The results of the study rely on proving the hypothesis that the two cohorts are similar and the treatments different. The authors largely succeed in this; however, they critically omit to deal with selection bias inherent in the non-randomised treatment assignment of the two groups.

The methodology section states that the criteria for ventilatory support were as follows: intubation, '...when ventilatory support was mandated...' and nCPAP, '....applied in the case of acute respiratory failure as defined by (a precise definition which is based on clinical signs, RSV apnoea and $\left.\mathrm{P}_{\mathrm{tc}} \mathrm{CO}_{2}\right) \ldots$.. These criteria are different and as such we cannot be sure that all the patients who received nCPAP would necessarily have been intubated. The similar number of episodes hospitalized in PICU during the two study periods without ventilatory support is indirect and insufficient evidence to explain whether selection bias had a role in determining treatment in the two ventilatory support groups.

A superior methodology that accounts for selection bias would have been to adjust on the basis of a propensity score constructed from patient-specific prognostic characteristics at the time of treatment assignment [2]; specifically these are the criteria of acute respiratory failure for nCPAP and those of 'mandated' intubation (which is not defined in the text). There is a further level of complexity regarding treatment assignment due to the uncertainty as to whether the same criteria for respiratory support were used by the physicians who intubated $81 \%$ of children in the first period and applied $55 \%$ of nCPAP in the second period prior to PICU admission.

Between the two identical study periods there was a remarkable $58 \%$ increase in treated episodes of severe bronchiolitis which is unexplained in the article. In the absence of an increase in the number of available beds and/or important changes in population demographics, neither of which is mentioned in the article, this suggests that the increase in episodes treated with nCPAP in the second period was indeed due to different assignment to the two treatment groups.

The high level of complications when using tracheal intubation for severe bronchiolitis, which has already been established in several studies [3, 4], is sufficient in itself to validate the discontinuation of intubation for the majority of cases.

If the retrospective observational nature of this study did not permit accuracy and lucidity regarding treatment assignment then the authors are not justified in their claim that this is the "first study to clearly demonstrate the clinical and economic benefit of nCPAP in severe acute bronchiolitis'.

Conflicts of interest None.

\section{References}

1. Essouri S, Laurent M, Chevret L, Durand P, Ecochard E, Gajdos V, Devictor D, Tissieres P (2014) Improved clinical and economic outcomes in severe bronchiolitis with pre-emptive nCPAP ventilatory strategy. Intensive Care Med 40:84-91. doi:10.1007/s00134-013-3129-z

2. D'Agostino RB Jr (1998) Propensity score methods for bias reduction in the comparison of a treatment to a nonrandomized control group. Stat Med 17:2265-2281

3. Jorgensen J, Wei J, Sykes K, Klem S, Weatherly R, Bruegger D, Latz A, Nicklaus P (2007) Incidence of and risk factors for airway complications following endotracheal intubation for bronchiolitis. Otolaryngol Head Neck Surg 137:394-399

4. Kneyber M, Blusse van Oud-Alblas H, van Vliet M, Uiterwaal C, Kimpen J, van Vught A (2005) Concurrent bacterial infection and prolonged mechanical ventilation in infants with respiratory syncytial virus lower respiratory tract disease. Intensive Care Med 31:680-685

\section{P. Jones $\cdot$ S. Dauger}

Réanimation Pédiatrique (PICU), Assistance Publique-Hôpitaux de Paris, Hôpital Robert Debré, 48 Bd Sérurier, 75019 Paris, France

\section{P. Jones $(\bowtie)$}

Portex Unit, University College London Institute of Child Health, 30 Guilford Street, London WC1N 1EH, UK

e-mail: sejjprj@live.ucl.ac.uk 